\title{
Risk Factors for Urinary Tract Infection in Hospitalized Patients
}

\section{Hadiati Setyorini $^{1}$, Artaria Tjempakasari ${ }^{2}$, Nunuk Mardiana $^{2^{*}}$}

${ }^{1}$ Department of Internal Medicine, Faculty of Medicine, Universitas Airlangga, Surabaya, Indonesia - Dr. Soetomo General Hospital Surabaya, Indonesia

${ }^{2}$ Nephrology Division, Department of Internal Medicine, Faculty of Medicine, Universitas Airlangga, Surabaya, Indonesia Dr. Soetomo General Hospital Surabaya, Indonesia

\section{A R T I C L E I N F O}

\section{Article history:}

Received 23 January 2019

Received in revised form 29 May 2019

Accepted 10 June 2019

Available online 30 June 2019

\section{Keywords:}

Urinary tract infection,

Geriatric age,

Urinary catheter,

Urolithiasis,

Diabetes,

Immobilization.

\section{*) Corresponding author:}

nunuk.mardiana@yahoo.com

\begin{abstract}
A B S T RA C T
Introduction: Urinary tract infection (UTI) is the most common infection that can be fatal and has higher rate mortality especially in some patient. This study is aim to analyze risk factors for urinary tract infection in hospitalized patients for prevention and more aggressive approach can be taken. Methods: Consecutively, medical records of 285 patients with urinary analysis was recorded for risk factors and urine culture results if suspected UTI. Risk factors for sex, age, urinary catheter, urolithiasis, DM, and immobilization was analyzed with bivariate analysis and multivariate analysis. Results: From 285 patients, 92 patients had UTI with average age was 52.45 years old, 48 $(56.49 \%)$ were female. Most common pathogen were E. coli $(41.3 \%)$, Enterobacter sp. $(8.8 \%)$ and Enterococcus faecalis ( $7.6 \%$ ). From bivariate analysis, geriatric age ( $>60$ years) has RR 1.421 (95\% CI 1.015-1.989, $\mathrm{p}=0.046)$ and immobilization has RR 1.861 (95\% CI 1.266-2.738, $\mathrm{p}=0.007)$, whereas sex (RR $1.19095 \%$ CI $0.851-1.664, \mathrm{p}=0.310$ ), diabetes (RR 1.171 95\% CI $0.833-1.645$, $\mathrm{p}=0.367$ ), insulin usage (RR $0.90095 \%$ CI $0.519-1.561, \mathrm{p}=0.703$ ), glycosuria (RR $1.15295 \%$ CI $0.741-1.791, \mathrm{p}=0.522$ ), and CKD (RR $1.47595 \%$ CI $0.896-2.430, \mathrm{p}=0.126$ ) give insignificant result. From multivariate analysis, urinary catheter has OR $4.506(95 \%$ CI 2.312-8.872, p=0.000), urolithiasis with OR 4.970 (95\% CI 1.931-12.787, $\mathrm{p}=0.001)$, and hyperglycemia has OR 2.871 (95\% CI 1.485-5.551, $\mathrm{p}=0.002)$.

Conclusion: Geriatric age and immobilization are risk factors for urinary tract infection, and urinary catheter, urolithiasis, and hyperglycemia are independent risk factors for urinary tract infection.
\end{abstract}

\begin{abstract}
Introduction
Urinary tract infection (UTI) is one of the most common infection with wide range of severity. According to NHAMCS (National Hospital Ambulatory Care Survey) and NAMCS (National Ambulatory Care Survey), UTI prevalence in community is approximately $0.7 \%$ and resulting in 40.9 million outpatient visit between 2006 and 2010, 24\% of which occured in ER. ${ }^{1,2}$ Indonesian Health Ministry estimating there are 90-100 UTI cases per 100.000 population per year or around 180.000 new cases per year. ${ }^{3}$ In Manado, prevalence of UTI reach $24 \%$ in outpatient clinic. ${ }^{4}$ This disease can occured asymptomatically where patients show minimal to no symptoms to severe bacteremia which caused sepsis and mortality. This happens especially in patients with risk factors such as defect and anomaly in anatomical structure or immunity, prompting more serious and recurrent infection, and in the end can causing permanent injury in kidney and ureter or urethra, even leading to sepsis and mortality. ${ }^{5,6}$ A study involving 710 participant showed that $27.9 \%$ UTI can develop bacteremia, $11.3 \%$ become shock, with overall mortality rate $0.28 \%{ }^{7}$ Some of this group can be found in daily practice such as older age, patients with diabetes, urinary catheter, urolithiasis, or immobilized patient. These patients also more vulnerable to
\end{abstract}

antibiotic-resistant microbes, giving challenge to treatment of UTI. Identification of these risk factors is important so we can take precautionary steps or give more agressive treatment in susceptible patients.

\section{Methods}

This study was an observational analitic study design in Dr. Soetomo General Hospital Surabaya from February until August 2018. Data was collected secondary from medical record using consecutive sampling. The inclusion criteria was all hospitalized patient who suspected for UTI underwent urinalysis as screening. We excluded if patient was pregnant, had been using immunosupressant or immunocompromised, had polycistic kidney disease, and had been using SGLT2 inhibitors. We recorded all data on sex, age, immobilization present, renal function, history of diabetes, indwelling urinary catheter, and urolithiasis, as risk factors and result of urinalysis and urin culture as diagnostic standard for diagnosing UTI. Urine culture done in Micorbiology Department in Dr Soetomo General Hospital, using Mac Conkey jelly with 3 days incubation period. 
The primary outcome was UTI risk factors analyzed in bivariate analysis using chi square test, and variable with significant $p$-value $>0,25$ will be included in mulitvariate analysis. We planned this study with target sample size at least 232 patient to achieve $80 \%$ power and a two-sided $\alpha$-value $=0.05$, assuming with UTI prevalence in risk group $10.7 \%$ and non-risk group $1.82 \%$.

\section{Results}

From total 285 patients, there were 92 patients with UTI and 193 had no infection. Characteristics of study patients by urinary tract infection and non-infection status are shown in Table 1. Overall, there were more women patient than men with 161 female and 124 male with most patients aged more than 5 decades old. The average age for overall patients are 52.45 years old.

The most common co-infection in our study were pulmonary infection $(13.3 \%)$, diabetic ulcer $(7.7 \%)$, and gastrointestinal infection (4.2\%). Other unclassified infection in UTI group was renal abcess ( 1 case), and in non UTI group were neck abcess ( 1 case), gluteal abcess ( 1 case), liver abcess (1 case), spontaneus bacterial peritonitis (1 case), and morbus hansen (1 case).

The most common comorbids in our patient population were chronic kidney disease (CKD) (44.6\%), diabetes mellitus (DM) (38.59\%), and hypertension (30.5\%). (Table 1$)$

There were total 92 positive culture from urine samples.
The most common pathogen isolated in patients with UTI were Escherichia coli (41.3\%), followed by Enterobacter sp. (8.8\%) and Enterococcus faecalis (7.6\%). There were 3 (3.3\%) patients with Methicillin Resistant Staphylococcus Aureus (MRSA) amongst $S$. aureus infection and 32 (34.78\%) patient with Extended Spectrum Beta-Lactamase (ESBL) infection with all ESBL pathogen were E. coli. Klebsiella pneumonia and Pseudomonas each has $5(5.4 \%)$ and $2(2.2 \%)$ patients. We found only 7 (7.6\%) patients with fungal infection, all from Candida sp. Urine culture result was shown in Table 2.

The most common risk factor was diabetes with 110 patients followed by geriatric age and urinary catheter. Among the UTI cases, in bivariate analysis, the most prominent risk was urinary catheter, followed by urolithiasis, immobilization and geriatric age (>60 years) with RR 2.125 (95\% CI 1.548 $-2.917, \mathrm{p}=0.000), 1.793$ (95\% CI $1.175-2.737, \mathrm{p}=0.020)$, $1.861(95 \%$ CI $1.266-2.738, \mathrm{p}=0.007)$, and $1.421(95 \% \mathrm{CI}$ $1.015-1.989 \mathrm{p}=0.046$ ) respectively. History of diabetes gave a weak result, but when the criteria changed into hyperglycaemia (plasma blood glucose $>200 \mathrm{mg} / \mathrm{dL}$ ) it give a significant risk with RR 1.526 (95\% CI $1.070-2.175, \mathrm{p}=0.027)$.

When analyzed in multivariate linear regression, the independent risk factors was urinary catheter, urolithiasis, and hyperglycaemia with OR 4.506 (95\% CI 2.312-8.872, $\mathrm{p}=0.000), 4.970(95 \%$ CI 1.931-12.787, $\mathrm{p}=0.001), 2.871(95 \%$ CI $1.485-5.551, \mathrm{p}=0.002)$ respectively. All analysis results from bivariate and multivariate analysis can be seen in Table 3 .

Table 1 Patient Characteristic

\begin{tabular}{|c|c|c|c|}
\hline Variables & $\begin{array}{c}\text { UTI (\%) } \\
\text { n=92 }\end{array}$ & $\begin{array}{c}\text { Non UTI (\%) } \\
n=193 \\
\end{array}$ & $\begin{array}{c}\text { Total }(\%) \\
n=285\end{array}$ \\
\hline \multicolumn{4}{|l|}{ Sex } \\
\hline Men & $44(47.8 \%)$ & $80(28 \%)$ & $124(43,5 \%)$ \\
\hline Women & $48(52.2 \%)$ & $113(40 \%)$ & $161(56,5 \%)$ \\
\hline Age (years, mean/max-min) & $55.38 / 19-89$ & $51.06 / 19-88$ & $52.45 / 19-89$ \\
\hline Geriatric age ( $>60$ years old $)$ & $35(38 \%)$ & $51(26.4 \%)$ & $86(30.2 \%)$ \\
\hline Blood glucose (mg/dL, mean/max-min) & $173.36 / 53-996$ & $157.33 / 49-909$ & $162.50 / 49-996$ \\
\hline eGFR (mean/max-min) & $51.88 / 2.48-170.83$ & $64.56 / 2.56-280.9$ & $60.47 / 2.48-280.9$ \\
\hline \multicolumn{4}{|l|}{ Comorbids } \\
\hline \multicolumn{4}{|l|}{ Other infection } \\
\hline $\begin{array}{l}\text { Pulmonary infection (pneumonia, bronchiectasis, } \\
\text { tuberculosis) }\end{array}$ & $11(11.9 \%)$ & $27(14 \%)$ & $38(13.3 \%)$ \\
\hline Gastrointestinal infection & $1(1.1 \%)$ & $11(5.7 \%)$ & $12(4.2 \%)$ \\
\hline Diabetic ulcer & $11(11.9 \%)$ & $11(5.7 \%)$ & $22(7.7 \%)$ \\
\hline Decubitus ulcer & $3(3.3 \%)$ & $1(0.5 \%)$ & $4(1.4 \%)$ \\
\hline Hepatitis & $2(2.2 \%)$ & $6(3.1 \%)$ & $8(2.8 \%)$ \\
\hline Others & $1(1.1 \%)$ & $5(2.6 \%)$ & $6(2.1 \%)$ \\
\hline \multicolumn{4}{|l|}{ Non infection } \\
\hline Diabetes mellitus & $39(42.4 \%)$ & $71(36.8 \%)$ & $110(38.59 \%)$ \\
\hline Cardiovascular disease & $10(10.9 \%)$ & $11(5.7 \%)$ & $21(7.4 \%)$ \\
\hline Hypertension & $21(22.8 \%)$ & $66(34.2 \%)$ & $87(30.5 \%)$ \\
\hline CKD & $47(51.1 \%)$ & $80(41.5 \%)$ & $127(44.6 \%)$ \\
\hline Chirrosis & $2(2.2 \%)$ & $12(6.2 \%)$ & $14(4.9 \%)$ \\
\hline Urolithiasis & $15(16.3 \%)$ & $10(5.1 \%)$ & $25(8,77 \%)$ \\
\hline Immobilization & $15(16.3 \%)$ & $12(6.2 \%)$ & $27(9.5 \%)$ \\
\hline Urinary catheter usage & $32(34.8 \%)$ & $29(15.0 \%)$ & $61(21,40 \%)$ \\
\hline
\end{tabular}


Table 2. Microbes from Urine Culture

\begin{tabular}{|c|c|c|}
\hline & Number of cases & $\%$ \\
\hline Acinetobacter baumanii & 5 & 5.4 \\
\hline Acinetobacter spp & 1 & 1.1 \\
\hline Burkholderia cepacia & 1 & 1.1 \\
\hline Candida albicans & 2 & 2.2 \\
\hline Candida galbrata & 1 & 1.1 \\
\hline Candida parapsilosis & 1 & 1.1 \\
\hline Candida rugose & 1 & 1.1 \\
\hline Candida tropicalis & 2 & 2.2 \\
\hline Escerichia coli & 38 & 41.3 \\
\hline Escerichia fergusonii & 1 & 1.1 \\
\hline Enterobacter aerogenes & 1 & 1.1 \\
\hline Enterobacter amigenous & 1 & 1.1 \\
\hline Enterobacter baumanii & 3 & 3.3 \\
\hline Enterobacter cloacae & 2 & 2.2 \\
\hline Enterococcus faecalis & 7 & 7.6 \\
\hline Pasteurella multicoda & 1 & 1.1 \\
\hline Klebsiella oxytoca & 1 & 1.1 \\
\hline Klebsiella pneumonia & 5 & 5.4 \\
\hline Pseudomonas aeruginosa & 2 & 2.2 \\
\hline Pseudomonas fluorescens & 1 & 1.1 \\
\hline Staphylococcus aureus & 4 & 4.3 \\
\hline Staphylococcus epidermidis & 4 & 4.3 \\
\hline Staphylococcus haemolyticus & 5 & 5.4 \\
\hline Staphylococcus saprophyticus & 1 & 1.1 \\
\hline Streptococcus agalactiae & 1 & 1.1 \\
\hline Streptococcus gordonii & 2 & 2.2 \\
\hline Total & 92 & 100 \\
\hline
\end{tabular}

Tabel 3 Bivariate and multivariate analysis of UTI risk factors

\begin{tabular}{lcccc}
\hline \multirow{2}{*}{ Variable } & \multicolumn{2}{c}{ Bivariate Analysis } & \multicolumn{2}{c}{ Multivariate Analysis } \\
\cline { 2 - 5 } RR (95\% CI) & p-value & OR (95\% CI) & p-value \\
\hline Geriatric age & $1.421(1.015-1.989)$ & 0.046 & $1.291(0.711-2.345)$ & 0.410 \\
Sex (male) & $1.190(0.851-1.664)$ & 0.310 & - & - \\
Urinary catheter & $2.125(1.548-2.917)$ & 0.000 & $4.506(2.312-8.872)$ & 0.000 \\
Urolithiasis & $1.793(1.175-2.737)$ & 0.020 & $4.970(1.931-12.787)$ & 0.001 \\
Diabetes & $1.171(0.833-1.645)$ & 0.367 & - & - \\
Insulin usage & $0.900(0.519-1.561)$ & 0.703 & - & - \\
Hyperglycemia & $1.526(1.070-2.175)$ & 0.027 & $2.871(1.485-5.551)$ & 0.002 \\
Glycosuria & $1.152(0.741-1.791)$ & 0.522 & - & - \\
Immobilization & $1.861(1.266-2.738)$ & 0.007 & $2.001(0.808-4.956)$ & 0.134 \\
CKD & $1.475(0.896-2.430)$ & 0.126 & - & - \\
\hline
\end{tabular}




\section{Discussion}

Urinary tract infection (UTI) usually commonly found in female in general population, and most of the research studying this disease usually conclude. ${ }^{8,11}$ Previous studies done in various setting and hospital, like one study by Lee and colleagues in intensive care patients in Australia with $68 \%$ reported patients with symptomatic UTI were female. ${ }^{9}$ But in this study, although female patient was indeed more than male, those who had positive urine culture tended to be male, even though not statistically significant. This result contradicting popular believe that female is more susceptible to UTI, it might due to our study population inclined to be patients aged over the fifth decades. In older population, UTI is more common in the male counterpart, because there are emerging comorbidities that showed in older age, such as prostate hypertrophy. Older adults also prone to genitourinary abnormalities that impair voiding such as urinary incontinence. ${ }^{12}$ Other reason is in a hospital setting, patient is prone to catheterization that breaching anatomical barrier from UTI, the urethra spincter; and providing a way for uropathogen which nullified the male anatomical advantage. Also, our data was taken from a tertiary referral hospital, where most patients have multiple comorbid that might affect the anatomical or functional capacity of urinary tract defence against pathogen invasion. This result is in accordance with other study with population based on hospitalized patient or ICU setting at tertiary referral hospital in Calgary, Canada. ${ }^{13}$

Urine is normally sterile and germ free. The most common source of infection usually comes from microorganism colonization in anus and perineum that goes through urethra, so UTI pathogens usually are normal intestinal flora which translocated to urinary tract. ${ }^{14} \mathrm{E}$. coli is predominant pathogen responsible for UTI, as presented by this study and other studies concerning UTI in various population. ${ }^{10,15,16}$ Appearance of antibiotic-resistant microorganisms such as MRSA and ESBL, along with $K$. pneumoniae and P. aeruginosa suggest a nosocomial infection. Such high incidence will provide a significant challenge for antibiotic selection and treatment.

We found that old age, and immobilization as risk factor for UTI even though multivariate analysis shown that they were not the true independent risk factor for UTI. This suggests that despite immobilized patients and old age increase risk of infection, there are other components that can affect the probability. For instance, there were question regarding personal hygiene and whether patient used indwelling urinary catheter, non-invasive urinary catheter or only diapers. There are also various comorbids that need to be assessed such as neuropathy that caused incontinence, prostate hyperplasia that cause urine stasis, menopause, hormone treatment and so forth. ${ }^{12}$

Surprisingly, diabetes mellitus, a widely known risk factor for UTI gave an insignificant result. This result became different when we changed the criteria from diabetes to hyperglycaemia. This showed that a poor glycaemic control, whether cause by diabetes or a simply reactive hyperglycemia, contribute more for risk of infection than diabetes status. This may be attributed to impairment of host defenses, including decreased polymorphonuclear leukocyte mobilization, chemotaxis, and phagocytic activity related to hyperglycemia. ${ }^{17}$ This also highlighted the importance of good glycemic control especially in critically ill patient and diabetes who prone to increase in blood glucose.

Catheter-associated urinary tract infection is one of the most common device-associated infection in hospital. ${ }^{18}$ Sadly, this is a preventable disease that caused morbidity and mortality in hospitalized patient. A study in Columbia and Puerto Rico stated that it is especially true amongst intensive care patient, and a national prevention program can reduce catheter use and infection rate. ${ }^{19}$ Duration of catheterization is the predominant risk for this infection, and early removal will significantly improve the rates. ${ }^{20}$

UTI is very common in patient with urolithiasis. This becomes more complicated when urease-producing bacteria involved, which forming infection stones consisting of monoamminium urate, struvit, and/ or carbonate apatite that branchinng and encompass the renal pelvis and calyces, or as we usually know as staghorn calculi. ${ }^{21,16}$ Patient with older age, obstruction and multiple stones were said to be also more prone to infection. ${ }^{16}$ Unfortunately our study had no data about type and number of stone hence we could not analyze further.

This study has limitations. Because our source of data were medical records, we could not control the examination and screening done to the patient, hence there might be some loss or bias due to incomplete data. Further studies using cohort or case control methods may give more valuable insight to what are the risk factors for UTI in hospitalized patient, which most likely different form those in community or outpatient setting due to unique circumstance and multiple comorbid and iatrogenic procedure.

\section{Conclusion}

Urinary catheter, urolithiasis, and hyperglycaemia were independent risk factors for UTI in hospitalized patients. Older age and immobilization were also other important risk factors, although they might be influenced by another factor. Hospitalized patients with these risk factors needed to be screened for UTI. Further study with more specific population might provide valuable additional data regarding sub factors in each risk factor that affect UTI incidence in hospitalized patients.

\section{Conflict of Interest}

The author stated there is no conflict of interest

\section{References}

1. May L, Mullins P, Pines J. Demographic and Treatment Patterns for Infections in Ambulatory Settings in the United States, 2006-2010. Wilbur L, editor. Acad Emerg Med. 2014 Jan;21(1):17-24.

2. Centers for Disease Control and Prevention. Ambulatory Medical Care Utilization Estimates for 2017. 2007.

3. Depkes RI. Survey Demografi dan Kesehatan Indonesia. Jakarta; 2014.

4. Mosesa SP, Kalesaran AFC, Kawatu PAT. Faktor-faktor yang Berhubungan dengan Kejadian Infeksi Saluran Kemih pada Pasien Poliklinik Penyakit dalam di RSU GMIM Pancaran Kasih Manado. Vol. 897. 2016

5. Foxman B. Urinary Tract Infection Syndromes. Occurrence, 
Recurrence, Bacteriology, Risk Factors, and Disease Burden. Infect Dis Clin North Am [Internet]. 2014;28(1):1-13. A

6. Flores-Mireles AL, Walker JN, Caparon M, Hultgren SJ. Urinary tract infections: Epidemiology, Mechanisms of Infection and Treatment Options. Nat Rev Microbiol. 2015;13(5):269-84.

7. Hsiao C, Yang H, Chang C, Lin H, Wu C, Hsiao M, et al. Risk Factors for Development of Septic Shock in Patients with Urinary Tract Infection. Biomed Res Int. 2015;2015:1-7.

8. Castle N, Engberg JB, Wagner LM, Handler S. Resident and Facility Factors Associated with the Incidence of Urinary Tract Infections Identified in the Nursing Home Minimum Data Set. J Appl Gerontol. 2017;36(2):173-94.

9. Lee EK, Teo A, Land G, Borrell S, Spelman D, Leong T, et al. Risk Factors Associated with Urinary Tract Infections in Intensive Care Patients. Infect Dis Heal. 2016;21(2):62-6.

10. Chiţă T, Timar B, Muntean D, Bădiţoiu L, Horhat F, Hogea E, et al. Urinary Tract Infections in Romanian Patients with Diabetes: Prevalence, Etiology, and Risk Factors. Ther Clin Risk Manag. 2017;13:1-7.

11. Boyko EJ, Fihn SD, Scholes D, Chen CL, Normand EH, Yarbro P. Diabetes and the Risk of Acute Urinary Tract Infection Among Postmenopausal Women. Diabetes Care. 2002;25(10):1778-83.

12. Nicolle LE. Urinary Tract Infections in the Older Adult. Clin Geriatr Med. 2016;32(3):523-38.

13. Laupland KB, Zygun DA, Davies HD, Church DL, Louie TJ, Doig CJ. Incidence and Risk Factors for Acquiring Nosocomial Urinary Tract Infection in the Critically ill. J Crit Care. 2002;17(1):50-7.
14. Vasudevan R. Urinary Tract Infection: An Overview of the Infection and the Associated Risk Factors. J Microbiol Exp. 2014;1(2):1-15.

15. Van Der Kooi TII, De Boer AS, Manniën J, Wille JC, Beaumont MT, Mooi BW, et al. Incidence and Risk Factors of Device Associated Infections and Associated Mortality at the Intensive Care in the Dutch Surveillance System. Intensive Care Med. 2007;33(2):271-8.

16. Yongzhi L, Shi Y, Jia L, Yili L, Xingwang Z, Xue G. Risk factors for Urinary Tract Infection in Patients with Urolithiasis - Primary Report of a Single Center Cohort. BMC Urol. 2018;18(1):1-6.

17. Butler SO, Btaiche IF, Alaniz C. Relationship Between Hyperglycemia and Infection in Critically Ill Patients Outline Normal Glucose Metabolism Glucose Metabolism in Critical Illness Hyperglycemia Definition Complications Pathogenesis of Hyperglycemia-Associated Infection Hyperglycemia an. Pharmacotherapy. 2005;25(7):963-76.

18. World Health Organization. Report on the Burden of Endemic Health Care-Associated Infection Worldwide Clean Care is Safer Care. World Heal Organ. 2011;1-40.

19. Saint S, Greene MT, Krein SL, Rogers MAM, Ratz D, Fowler KE, et al. A Program to Prevent Catheter-Associated Urinary Tract Infection in Acute Care. N Engl J Med. 2016 Jun 2;374(22):2111-9.

20. Chenoweth C, Saint S. Preventing Catheter-Associated Urinary Tract Infections in the Intensive Care Unit. Crit Care Clin. 2013;29(1):1932.

21. Bichler K, Eipper E, Naber K, Braun V, Zimmermann R, Lahme S. Urinary infection stones. Int J Antimicrob Agents. 2002 Jun;19(6):488-98. 